\title{
Circulating miR-122 and miR-192 as Specific and Sensitive Biomarkers for Drug-Induced Liver Injury with Acetaminophen in Rats
}

\author{
Pouria Jarsiah ${ }^{1}$, Mohammad Karami ${ }^{1}$, Anahita Nosrati ${ }^{2}$, Ahad Alizadeh ${ }^{3}$ and Mohammad Bagher \\ Hashemi-Soteh ${ }^{4, *}$ \\ ${ }^{1}$ Department of Toxicology and Pharmacology, Faculty of Pharmacy, Mazandaran University of Medical Sciences, Sari, Iran \\ ${ }^{2}$ Laboratory of Pathobiology, Imam Khomeini Hospital, Sari, Iran \\ ${ }^{3}$ Department of Epidemiology and Reproductive Health, Reproductive Epidemiology Research Center, Royan Institute for Reproductive Biomedicine, ACECR, Tehran, Iran \\ ${ }^{4}$ Immunogenetic Research Center, Molecular and Cell biology Research Center, Faculty of Medicine, Mazandaran University of Medical Sciences, Sari, Iran \\ Corresponding author: Immunogenetic Research Center, Molecular and Cell biology Research Center, Faculty of Medicine, Mazandaran University of Medical Sciences, Sari, \\ Iran. Email: hashemisoteh@gmail.com
}

Received 2017 December 28; Revised 2018 April 15; Accepted 2018 May 14.

\begin{abstract}
Background: Acetaminophen (APAP) poisoning is the most common drug intoxication, which often leads to acute liver failure and necrosis of liver tissue following the use of its excessive amounts.

Objectives: In this study, the effects of toxic and therapeutic doses of acetaminophen were assessed on miR-122 and miR-192 compared to aminotransferase (AST and ALT) and liver pathological lesions in rats at the first and third hours of injection.

Methods: In this study, 32 male Sprague-Dawley rats were randomly selected and divided into eight groups (four groups for the first-hour and four groups for the third-hour injection). In the case groups, three groups after one hour and three groups after three hours of injecting with APAP doses $(75,150$, and $300 \mathrm{mg} / \mathrm{kg} \mathrm{bw})$ intraperitoneally were sampled and killed. Changes in necropsy and macroscopic features of the rat liver were recorded after staining. The plasma levels of miR-122 and miR-192 were evaluated using the real-time PCR method and plasma levels of liver enzymes such as AST and ALT were measured by using an automated analyzer. Results: The histopathological examination at the dose of $150 \mathrm{mg} / \mathrm{kg}$ revealed mild hyperemia and edema in the portal areas, as well as mild infiltration of inflammatory cells. Centrilobular necrosis was mild at $300 \mathrm{mg} / \mathrm{kg}$. ALT and AST activities were not significantly different between the case and control groups at the first hour, but they were significant between the groups receiving APAP for three hours. Moreover, the results of miRNA were significant at different times and doses $(\mathrm{P}<0.05)$.

Conclusions: Due to the ability to induce a protective system against acetaminophen toxicity, the plasma level of miR-122 and miR192 activity at the early hours will be more helpful than measuring ALT and AST levels $(\mathrm{P}<0.05)$.
\end{abstract}

Keywords: Acetaminophen, AST/ALT, miR-122, miR-192, Biomarker

\section{Background}

The liver is the primary metabolism site in the body that is usually subject to a high degree of exposure to medicines and external substances (1). Therefore, druginduced liver injury is the most important clinical problem that accounts for about $10 \%$ of the liver transplant cases and may lead to patient death (2). Acetaminophen is the most common drug metabolized by the liver and some of it at high doses is converted into the active metabolite of N-acetyl-p-benzoquinone imine (NAPQI) by the cytochrome P450 system, causing acute liver failure (3). The measurement of serum alanine aminotransferase (ALT) is a standard biomarker for the diagnosis and prognosis of liver injuries (4) that is released into the bloodstream due to injury to the cell membrane (5). However, ALT is not liver tissue-specific and can be released by injured cells of other organs such as kidneys, muscles, and heart (5).

An ideal biomarker should have low concentrations in the blood and other body fluids, and can be released into the circulatory system and measured quickly and accurately. MicroRNAs are noncoding and single-stranded molecules of intracellular regulating RNAs with 18 - 25 nucleotides in length (6) that adjust gene expression through the RNA interference (RNAi = RNA interference). miRNAs exist in a variety of body fluids, including blood (7), urine (8), and saliva (4) and control important processes such as development, differentiation, proliferation, and apoptosis (9). In addition to their role in regulating gene expression, serum miRNA levels are recently introduced as a new class of biomarkers for various diseases such as fibrosis (10), heart failure (11), and cancer (12). Many miRNAs are expressed in tissues and some of them show a high

Copyright (c) 2018, Jundishapur Journal of Natural Pharmaceutical Products. This is an open-access article distributed under the terms of the Creative Commons Attribution-NonCommercial 4.0 International License (http://creativecommons.org/licenses/by-nc/4.0/) which permits copy and redistribute the material just in noncommercial usages, provided the original work is properly cited. 
tissue specificity (13) such as miR-122, the most abundant miRNA in the liver (14); it is a multi-functional RNA(6) playing an important role in oxidative stress pathways (15) and metabolism of lipids (14). Although miR-122 is specific to liver tissue, it exists in small amounts in the heart tissue. Recent studies have shown that high serum levels of miR122 are associated with a range of liver diseases such as fibrosis, cancer, or viral infections.

Since miR-122 has a high specificity and is non-invasive, it is considered a good biomarker for liver diseases (5). miR-192, the other abundant miRNA in the liver (6), is a general gene expression regulator that helps TP53 suppressor function in the liver injury and has an anti-apoptosis role. In a previous study, Sanchari Roy showed that an increase in the serum level of miR-192 in mice indicated the liver injury. Considering that the level of alanine transaminase as the biomarker of liver injury is not detectable at least up to 12 hours after the ingestion of high doses of acetaminophen and since this time is very important for the development of liver injury (16).

\section{Objectives}

The aim of this study was to evaluate the use of miRNAs as reliable and suitable biomarkers for diagnosing acetaminophen-induced liver injuries, in comparison with the histopathology and enzyme assay.

\section{Methods}

\subsection{Chemicals}

APAP was purchased from the MERCK Company (St. Louis, USA). MicroRNA extraction was carried out using the miRNeasy Serum/Plasma kit (Qiagen, USA) while the miramp kit from Parsgenome Company (Iran) was used for miRNA amplification.

\subsection{Animal and Care Conditions}

A total of 32 white male Sprague-Dawley rats aged 6 to 32 weeks and weighing $180 \mathrm{~g}$ were randomly selected from the Laboratory Animal Research Center of Mazandaran University of Medical Sciences. The animals were kept in cages made of transparent polycarbonate at the appropriate temperature and humidity. They had adequate access to food and water. All test steps were performed according to the guidelines issued by the Ethics Committee for working with Laboratory Animals of Mazandaran University of Medical Sciences. The rats were later divided into eight groups (four rats each) and kept under similar conditions. Three groups were sampled in the first hour of injection and three other groups three hours after the injection.

Toxic and therapeutic doses $(75,150$, and $300 \mathrm{mg} / \mathrm{Kg}$ b.w) of acetaminophen were intraperitoneally injected to each rat in the experimental groups at a time. Phosphate buffered saline (PBS) $(100 \mathrm{mM}, \mathrm{pH}=7.40)$ was injected only into the two groups, each of which was used as a control for the first-hour and third-hour injections.

\subsection{Blood Chemistry and Histopathology}

After inducing full anesthesia using ether, blood samples were taken from the heart (cardiac puncture). Serum ALT and AST were measured by a Hitachi 911 autoanalyzer (Hitachi High-Technologies, Japan). After recording the macroscopic tissue changes, the liver of the tested rats was fixed in 10\% formalin. After routine pathological processing, five micrometer-thick sections were prepared and stained with hematoxylin and eosin.

To investigate four hepatocyte necrosis factors, inflammation of the portal region, inflammatory cell infiltration, necrosis of centrilobular area, and the reduction of cellular glycogen were used. The severity of hepatic injury rated from 0 to 3 ( $0=$ no injury; $1=$ mild injury; $2=$ moderate in jury; and 3 = severe injury) was studied and evaluated (17).

\section{4. microRNA Extraction}

The extraction process was carried out using kit column miRNeasy Serum/Plasma kit (Qiagen, USA) so that the first 200- $\mu \mathrm{L}$ volume of plasma samples was mixed with $1000 \mu \mathrm{L}$ of the QiAzol solution and the process of microRNA extraction continued according to the manufacturer's kit protocol. Finally, the product resulting from the extraction was kept in a freezer at $-80^{\circ} \mathrm{C}$ for later use.

\section{5. cDNA Synthesis and Real-Time PCR}

First, a polyA tail was added to the microRNA. To do so, the Parsgenome miR-Amp kit (Parsgenome Company, Iran) was used according to the manufacturer's protocol. Then, $2 \mu \mathrm{L}$ of the miRNA polyA tail product was used to make $20 \mu \mathrm{L}$ cDNA. The cDNA was made using Parsgenome MiRAmp universal cDNA synthesis kit according to the manufacturer's instruction.

The miRNA levels were measured by fluorescence signals generated by an SYBR Green probe during the realtime PCR in Bio-Rad IQ5 device (Bio-Rad, USA). $1.3 \mu$ L of specific primers were used to amplify cDNA in a total volume of $20 \mu \mathrm{L}$ reactions using the Parsgenome miR-Amp kit. Finally, the amount of expression of each miRNA was calculated using the Bio-Rad LQ5 software provided by the company (Bio-Rad, USA). Moreover, 5s rRNA was used as an internal control to study hepatic microRNAs in rats. It has been shown that 5 s rRNA has a regular and stable expression in plasma samples (18). 


\subsection{Statistical Analysis}

Quantitative data were expressed as means \pm SD. BoxCox transformation was used to normalize data due to nonhomogeneity of variances and the parametric tests were used accordingly. In addition, the correlation of the data was evaluated using the multivariate analysis of variance (MANOVA). The data were analyzed using SPSS V.21.3.0.2 and the $P$ value $<0.05$ was considered as a significant criterion in all the tests. GraphPad Prism V. 6 software was used for diagramming. The $\Delta \mathrm{Ct}$ method was used to determine the relative expression of miRNA levels, which was later normalized using $5 \mathrm{~S}$ rRNA. The data were reported as $2^{-\Delta \mathrm{Ct}}$ using the following formula: $\Delta \mathrm{Ct}=\mathrm{Ct}$ (miRNA of interest)- $\mathrm{Ct}$ (housekeeping). Finally, the level of change was expressed as 2 [-(mean of $\Delta \mathrm{Ct}$ values of treated samples - mean of $\Delta \mathrm{Ct}$ values of control samples)] (19).

\section{Results}

\subsection{Histopathological Analysis}

Histopathological data of this study have been reported recently (17). Briefly, the histopathological changes were seen in the liver of rats with $150 \mathrm{mg}$ acetaminophen injection in both one and three-hour tests in the form of hyperemia, mild edema in the portal area, and mild infiltration of inflammatory cells. At one-hour and three-hour injections of $300 \mathrm{mg}$ acetaminophen, mild centrilobular necrosis was seen, but the spotty necrosis of liver cells was slightly more in one hour than in three hours of $300 \mathrm{mg}$ injections (Table 1) (17).

\subsection{ALT and AST Levels in Blood}

The liver enzyme activity of this study has been reported recently (17). Briefly, AST or ALT blood levels were measured in all serum samples. Based on the multivariate analysis of variance (MANOVA), both main effects (dose and time) and their interactions were significant (dose: Wilks' $\lambda=0.228, \mathrm{P}<0.001$, time: Wilks' $\lambda=0.456, \mathrm{P}<0.001$, and their interaction: Wilks' $\lambda=0.493, \mathrm{P}=0.010)$. In other words, the rates of ALT activity (IU/L) at the dose of $\geq 75$ $\mathrm{IU} / \mathrm{L}$ at the first and third hours were significantly different from each other (dose 75 IU/L: $\mathrm{P}<0.002$, dose $150 \mathrm{IU} / \mathrm{L}: \mathrm{P}=$ 0.025, and dose $300 \mathrm{IU} / \mathrm{L}: \mathrm{P}<0.001$ ) (Table 2) (17).

\subsection{MiRNAs Level in Plasma}

The levels of miR-122 and miR-192, as well as 5s rRNA as a control, were examined in the plasma of rat model with acute liver injury using real-time PCR. The amounts of miR122 were increasing at 75, 150, and $300 \mathrm{mg} / \mathrm{kg}$ doses both at one and at three hours after injection. The observations showed that there was a statistically significant correlation between miR-122 and miR-192 $(\mathrm{R}=0.604$ and $\mathrm{P}<0.001)$.
Moreover, the present study revealed that there was a partial correlation between miR-122 and miR-192 $(\mathrm{R}=0.536$ and $\mathrm{P}<0.003)$ when the effect of dose and time was controlled (Table 3 and Figure 2).

The results of multivariate analysis of variance (MANOVA) and univariate analysis of variance are reported in Table 4. MANOVA showed the effects of time, dose, and their interaction were statistically significant. Wilks' $\Lambda$ showed that $28 \%$ of the variance of miR-122 and miR-192 was not explained by the level of interaction between time and dose (Wilks' $\Lambda=0.28, \mathrm{P}<0.001$ ). According to univariate analysis, the significance of the interaction term that was shown by the multivariate test was related to miR-122. Based on the result, $53.6 \%$ of the variance of miR-122 was explained by the level of interaction between time and dose (Partial $\eta^{2}=0.536, \mathrm{P}<0.001$ ).

\section{Discussion}

The prevalence of drug-induced liver injury has been reported over 10 to 15 cases per 100000 individuals per year (20). To date, only a few metabolites or enzymes have been used to assess the drug-induced liver injury. These tests include the determination of total serum bilirubin levels, activity of alkaline phosphatase, aspartate aminotransferase, and alanine transferase enzymes (21). Increases in these enzymes are usually related to biles and hepatocytes damages, but they are not specific only to liver damage. Although the ALT activity is generally susceptible to liver damage, it is not susceptible to time or kinetics (22). As a result, finding new biomarkers is important for early diagnosis and treatment. The present study investigated miR-122 and miR-192 as the biomarkers for APAP-induced liver injury in Sprague-Dawley rats at different doses of 75,150, and $300 \mathrm{mg} / \mathrm{kg}$ in the first and third hours, compared to liver enzymes and pathological observations. In the first hour of APAP drug administration, no particular changes in ALT enzyme activity were seen at different doses compared to the normal control. However, two folds of changes at ALT level were observed when it was evaluated after the third hour (17). ALT and AST levels rise during various diseases like kidney damage; so, they cannot be considered as specific biomarkers for liver injury.

The hepatotoxicity rat model used in the present study showed that miR-122 and miR-192 plasma levels increased due to liver injuries. miR-122 is a known biomarker for liver toxicity in rats (23), monkey (1), and humans $(16,24)$. The overexpression of miR-122 increases the level of P53, an important suppressor gene that causes apoptosis by regulating the PI3K (phosphoinositide 3-kinase)/Akt signaling pathway (25). Previous studies proposed miR-122 and miR192 as good candidate biomarkers that their levels increase both in plasma and in the liver during the drug-induced 
Table 1. Liver Histopathological Changes in Control and Case Groups After Acetaminophen Injection. Dose and Time Are Shown in the Rows and Different Grades of Patholog ical Changes Are Shown in the Columns ${ }^{a}$

\begin{tabular}{|c|c|c|c|c|c|c|c|c|}
\hline \multirow{2}{*}{ Pathology State/Groups } & \multicolumn{2}{|c|}{ Control } & \multicolumn{2}{|c|}{75} & \multicolumn{2}{|c|}{150} & \multicolumn{2}{|c|}{300} \\
\hline & 1h & $3 h$ & lh & $3 h$ & 1h & $3 h$ & $\mathbf{1 h}$ & $3 h$ \\
\hline \multicolumn{9}{|l|}{$\begin{array}{l}\text { Portal area inflammation } \\
\text { and hematoma }\end{array}$} \\
\hline Grade 0 & + & + & + & + & & & & \\
\hline Grade 1 & & & & & + & + & + & + \\
\hline \multicolumn{9}{|l|}{ Grade 2} \\
\hline \multicolumn{9}{|l|}{ Grade 3} \\
\hline \multicolumn{9}{|l|}{$\begin{array}{l}\text { Liver cell necrosis (spotty } \\
\text { necrosis) }\end{array}$} \\
\hline Grade 0 & + & + & + & + & + & + & & \\
\hline Grade 1 & & & & & & & & + \\
\hline Grade 2 & & & & & & & + & \\
\hline \multicolumn{9}{|l|}{ Grade 3} \\
\hline \multicolumn{9}{|c|}{$\begin{array}{l}\text { Infiltration of inflammatory } \\
\text { cells }\end{array}$} \\
\hline Grade 0 & + & + & + & + & & & & \\
\hline Grade 1 & & & & & + & + & & + \\
\hline Grade 2 & & & & & & & + & \\
\hline \multicolumn{9}{|l|}{ Grade 3} \\
\hline \multicolumn{9}{|l|}{$\begin{array}{l}\text { Centrilobular necrosis and } \\
\text { glycogen decrease in cell }\end{array}$} \\
\hline Grade 0 & + & + & + & + & + & + & & \\
\hline Grade 1 & & & & & & & + & + \\
\hline \multicolumn{9}{|l|}{ Grade 2} \\
\hline Grade 3 & & & & & & & & \\
\hline
\end{tabular}

${ }^{\mathrm{a}}+$, The level of changes detected in each group.

Table 2. ALT and AST Levels in the Plasma of Rats in the Control Group Treated with Acetaminophen

\begin{tabular}{l|c|c|c}
\hline \multirow{2}{*}{$\begin{array}{l}\text { Time, } \\
\mathbf{h}\end{array}$} & Dosage, $\mathbf{m g} / \mathbf{k g}$ & AST $($ Mean $\pm \mathbf{S D})$ & ALT $($ Mean $\pm \mathbf{S D})$ \\
\hline \multirow{3}{*}{$\mathbf{1}$} & Control & $183.5 \pm 6.5$ & $70.5 \pm 7$ \\
\cline { 2 - 4 } & 75 & $307.3 \pm 138$ & $70.5 \pm 8$ \\
\cline { 2 - 4 } & 150 & $227.5 \pm 40$ & $90.0 \pm 8$ \\
\cline { 2 - 4 } & 300 & $251.2 \pm 75$ & $78.0 \pm 7$ \\
\cline { 2 - 4 } & Control & $187.0 \pm 8$ & $68.2 \pm 10$ \\
\cline { 2 - 4 } & 75 & $365.5 \pm 156$ & $143.2 \pm 88$ \\
\cline { 2 - 4 } & 150 & $293.2 \pm 124$ & $151.5 \pm 65$ \\
\cline { 2 - 4 } & 300 & $347.5 \pm 135$ & $162.5 \pm 35$ \\
\hline
\end{tabular}

liver injury (26-28). MiR-122 was reported as the most abundant liver-specific miRNA, comprising about $70 \%$ of total hepatic microRNA (29). In a study, Wang et al. evaluated a total of 93 different menus from the liver and plasma in mice. Several microRNAs expressed in the liver were elevated in plasma, with miR-122 and miR-192 showing higher levels after acetaminophen treatment (26).

In line with previous studies, our research showed that miR-122 was highly expressed in the precentral and periportal areas. Statistical analysis of miR-122 and miR-192 results in this study showed that $60 \%$ of miR-122 and $87.4 \%$ of miR-192 were overexpressed by dose and time (Figure 2 ). These results indicated that miR-122 changes are diagnosed earlier than hepatic standard markers.

Antoine et al. investigated the biomarkers to identify patients with the APAP-induced liver injury who were admitted for the first time to the hospital (24). They showed that the level of miR-122 as a highly specific liver biomarker increased in these patients. $17 \%$ of their patients developed liver injury while $83 \%$ did not, according to the serum ALT level (24). For miR-122, the median values for patients with liver injury were $3.69(0.43-96.0)$ versus $0.21(0.07-0.81)$ for 

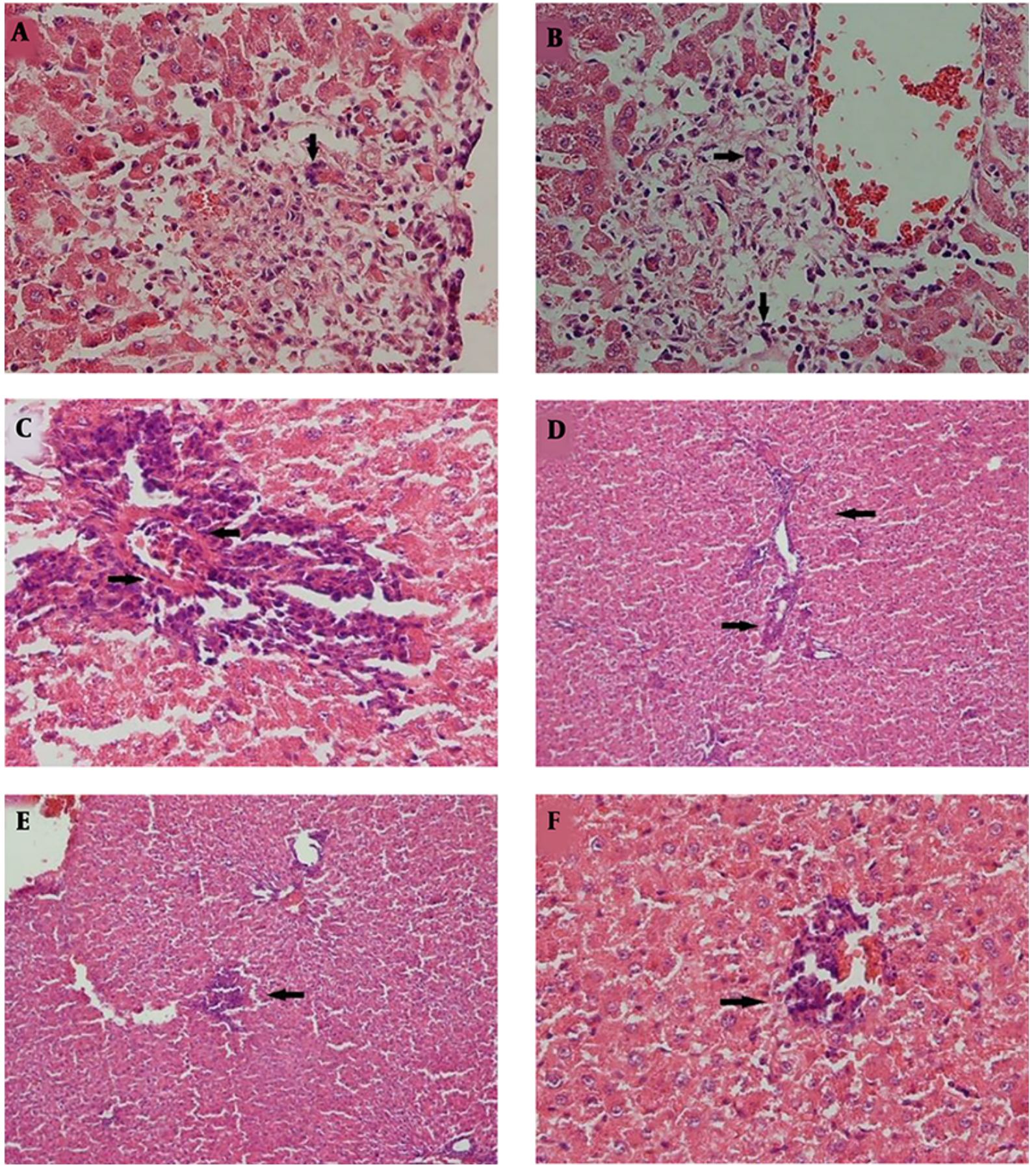

Figure 1. The histopathological changes observed in the livers of case rats at the doses of 150 and $300 \mathrm{mg} / \mathrm{kg}$. A, B, arrows show the centrilobular necrosis area; C, D, arrows show the portal tract inflammation area; E, F, arrows show the spotty necrosis area.

the patients who did not $\left(\mathrm{P}^{1} / 40.002\right)$.

Because of their size, frequency, tissue specificity, and relative stability in plasma, miRNAs can be considered as available exclusive markers to monitor tissue damages.
miR-122 as a liver-specific biomarker can be used to diagnose APAP-induced acute and chronic liver damage $(13,30)$.

The results of this study are consistent with those of previous studies that reported miR-122 and miR-192 
Jarsiah P et al.

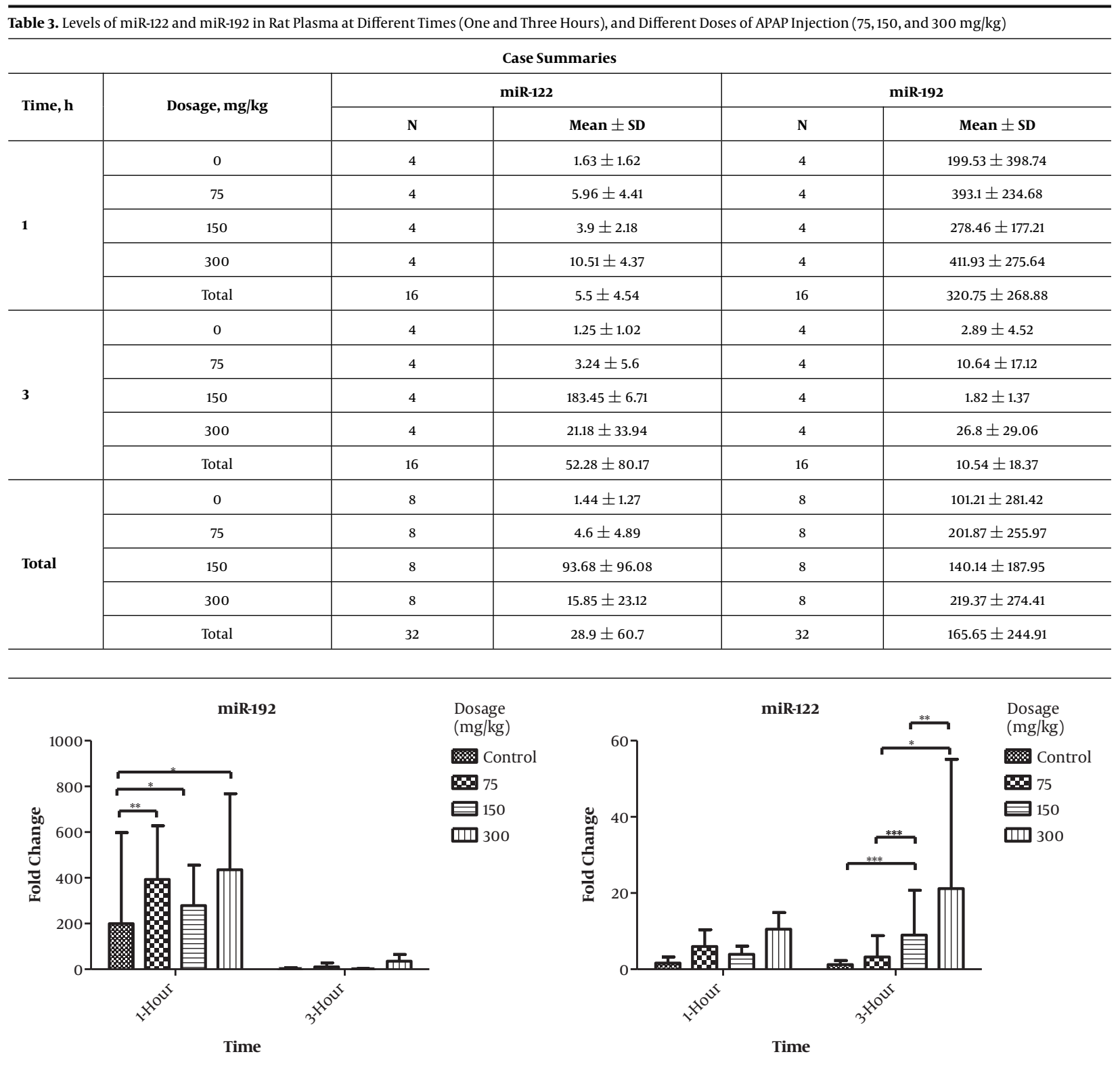

Figure 2. Changes of miR-122 and miR-192 levels in blood plasma of experimental rats. The amounts of miR-122 are increasing with 75, 150, and 300 mg/kg doses, both at one and at three hours after injection. The amounts of miR-192 are increasing after one hour of APAP injection, but not after three hours.

changes are diagnosed earlier than hepatic standard markers. miR-122 is more sensitive than ALT in response to dose and time and the liver injury can be diagnosed in the early phases of the follow-up. Inherently, miRNAs are more easily detected than other proteins. As our study and others shown, circulating miRNAs are stable and can be extracted and examined in every serum sample. Moreover, considering that miRNAs remain longer in biological samples than proteins, they can be suitable diagnostic markers in the liver injury. Finally, miR-122 and miR-192 may be more spe- cific for liver diseases in serum or plasma than ALT/AST enzymes.

\section{Acknowledgments}

This paper is the result of a Master's thesis in Toxicology by Pouria Jarsiah. We would like to appreciate the staff of the Animal Research Center of Mazandaran University of Medical Sciences. We also would like to thank Dr. Hadis Alidadi from the Ahvaz Jundishapur University of Medical Sciences and all those who helped us with this project. 


\begin{tabular}{|c|c|c|c|c|c|c|}
\hline \multirow{3}{*}{ Factors } & \multicolumn{2}{|c|}{ Multivariate } & \multicolumn{4}{|c|}{ Univariate } \\
\hline & \multirow{2}{*}{ Wilks' $\Lambda$} & \multirow{2}{*}{ P Value } & \multicolumn{2}{|c|}{ miR-192 } & \multicolumn{2}{|c|}{ miR-122 } \\
\hline & & & Partial $\eta^{2}$ & PValue & $\operatorname{Partial} \eta^{2}$ & P Value \\
\hline Time, h & 0.421 & $<0.001$ & 0.451 & $<0.001$ & 0.032 & 0.378 \\
\hline Dose, mg/kg & 0.274 & $<0.001$ & 0.357 & 0.013 & 0.605 & $<0.001$ \\
\hline $\begin{array}{l}\text { The interaction between time } \\
\text { and dose }\end{array}$ & 0.280 & $<0.001$ & 0.252 & 0.068 & 0.536 & $<0.001$ \\
\hline
\end{tabular}

${ }^{\mathrm{a}}$ The result has been computed under the natural logarithm transformation.

\section{Footnotes}

Conflict of Interests: The authors declare no conflict of interest.

Ethical Considerations: All test steps were performed according to the guidelines issued by the Ethics Committee for working with laboratory animals of Mazandaran University of Medical Sciences.

Funding/Support: This work was financially supported by grant 214-91 from the cellular and molecular biology research center of Mazandaran University of Medical Sciences.

\section{References}

1. Tamai S, Iguchi T, Niino N, Mikamoto K, Sakurai K, Sayama A, et al. A monkey model of acetaminophen-induced hepatotoxicity; phenotypic similarity to human. J Toxicol Sci. 2017;42(1):73-84. doi: 10.2131/jts.42.73. [PubMed: 28070111].

2. Fontana RJ. Acute liver failure due to drugs. Semin Liver Dis. 2008;28(2):175-87. doi: 10.1055/s-2008-1073117. [PubMed: 18452117].

3. Davis DC, Potter WZ, Jollow DJ, Mitchell JR. Species differences in hepatic glutathione depletion, covalent binding and hepatic necrosis after acetaminophen. Life Sci. 1974;14(11):2099-109. doi: 10.1016/00243205(74)90092-7. [PubMed: 4847802].

4. Ozer JS, Chetty R, Kenna G, Palandra J, Zhang Y, Lanevschi A, et al. Enhancing the utility of alanine aminotransferase as a reference standard biomarker for drug-induced liver injury. Regul Toxicol Pharmacol. 2010;56(3):237-46. doi: 10.1016/j.yrtph.2009.11.001. [PubMed: 19903504]

5. Thulin P, Hornby RJ, Auli M, Nordahl G, Antoine DJ, Starkey Lewis P, et al. A longitudinal assessment of miR-122 and GLDH as biomarkers of drug-induced liver injury in the rat. Biomarkers. 2017;22(5):461-9. doi: 10.1080/1354750X.2016.1269131. [PubMed: 27978773].

6. Starkey Lewis PJ, Dear J, Platt V, Simpson KJ, Craig DG, Antoine DJ, et al. Circulating microRNAs as potential markers of human drug-induced liver injury. Hepatology. 2011;54(5):1767-76. doi: 10.1002/hep.24538. [PubMed: 22045675].

7. Mitchell PS, Parkin RK, Kroh EM, Fritz BR, Wyman SK, PogosovaAgadjanyan EL, et al. Circulating microRNAs as stable bloodbased markers for cancer detection. Proc Natl Acad Sci U S A. 2008;105(30):10513-8. doi: 10.1073/pnas.0804549105. [PubMed: 18663219]. [PubMed Central: PMC2492472].

8. Hanke M, Hoefig K, Merz H, Feller AC, Kausch I, Jocham D, et al. A robust methodology to study urine microRNA as tumor marker: MicroRNA-126 and microRNA-182 are related to urinary bladder cancer. Urol Oncol. 2010;28(6):655-61. doi: 10.1016/j.urolonc.2009.01.027. [PubMed: 19375957].
9. Coulouarn C, Factor VM, Andersen JB, Durkin ME, Thorgeirsson SS. Loss of miR-122 expression in liver cancer correlates with suppression of the hepatic phenotype and gain of metastatic properties. Oncogene. 2009;28(40):3526-36. doi: 10.1038/onc.2009.211. [PubMed: 19617899]. [PubMed Central: PMC3492882].

10. Roderburg C, Luedde M, Vargas Cardenas D, Vucur M, Scholten D, Frey $\mathrm{N}$, et al. Circulating microRNA-150 serum levels predict survival in patients with critical illness and sepsis. PLoS One. 2013;8(1). e54612. doi: 10.1371/journal.pone.0054612. [PubMed: 23372743]. [PubMed Central: PMC3555785]

11. Ben-Shachar R, Chen Y, Luo S, Hartman C, Reed M, Nijhout HF. The biochemistry of acetaminophen hepatotoxicity and rescue: A mathematical model. Theor Biol Med Model. 2012;9:55. doi: 10.1186/1742-46829-55. [PubMed: 23249634]. [PubMed Central: PMC3576299].

12. Kong YW, Ferland-McCollough D, Jackson TJ, Bushell M. microRNAs in cancer management. Lancet Oncol. 2012;13(6):e249-58. doi: 10.1016/S1470-2045(12)70073-6. [PubMed: 22652233].

13. Yamaura Y, Nakajima M, Takagi S, Fukami T, Tsuneyama K, Yokoi T. Plasma microRNA profiles in rat models of hepatocellular injury, cholestasis, and steatosis. PLoS One. 2012;7(2). e30250. doi: 10.1371/journal.pone.0030250. [PubMed: 22363424]. [PubMed Central: PMC3281829].

14. Roderburg C, Benz F, Vargas Cardenas D, Koch A, Janssen J, Vucur M, et al. Elevated miR-122 serum levels are an independent marker of liver injury in inflammatory diseases. Liver Int. 2015;35(4):1172-84. doi: 10.1111/liv.12627. [PubMed: 25039534].

15. Reid G, Kirschner MB, van Zandwijk N. Circulating microRNAs: Association with disease and potential use as biomarkers. Crit Rev Oncol Hematol. 2011;80(2):193-208. doi: 10.1016/j.critrevonc.2010.11.004. [PubMed: 21145252].

16. Hornby RJ, Starkey Lewis P, Dear J, Goldring C, Park BK. MicroRNAs as potential circulating biomarkers of drug-induced liver injury: Key current and future issues for translation to humans. Expert Rev Clin Pharmacol. 2014;7(3):349-62. doi: 10.1586/17512433.2014.904201. [PubMed: 24694030].

17. Jarsiah P, Nosrati A, Alizadeh A, Hashemi-Soteh SMB. Hepatotoxicity and ALT/AST enzymes activities change in therapeutic and toxic doses consumption of acetaminophen in rats. Int Biolog Biomed J. 2017;3(3):119-24.

18. Cheung L, Gustavsson C, Norstedt G, Tollet-Egnell P. Sex-different and growth hormone-regulated expression of microRNA in rat liver. BMC Mol Biol. 2009;10:13. doi: 10.1186/1471-2199-10-13. [PubMed: 19236699]. [PubMed Central: PMC2654566].

19. Livak KJ, Schmittgen TD. Analysis of relative gene expression data using real-time quantitative PCR and the 2(-Delta Delta $C(T)$ ) Method. Methods. 2001;25(4):402-8. doi: 10.1006/meth.2001.1262. [PubMed: 11846609].

20. Rangnekar AS, Fontana RJ. An update on drug induced liver injury. Minerva Gastroenterol Dietol. 2011;57(2):213-29. [PubMed: 21587150].

21. Antoine DJ, Mercer AE, Williams DP, Park BK. Mechanism-based bioanalysis and biomarkers for hepatic chemical stress. Xenobiotica. 2009;39(8):565-77. doi: 10.1080/00498250903046993. [PubMed: 19621999]. 
22. Ozer J, Ratner M, Shaw M, Bailey W, Schomaker S. The current state of serum biomarkers of hepatotoxicity. Toxicology. 2008;245(3):194-205. doi:10.1016/j.tox.2007.11.021. [PubMed: 18291570].

23. Starckx S, Batheja A, Verheyen GR, Jonghe SD, Steemans K, Dijck BV, et al. Evaluation of miR-122 and other biomarkers in distinct acute liver injury in rats. Toxicol Pathol. 2013;41(5):795-804. doi: 10.1177/0192623312464436. [PubMed: 23143187].

24. Antoine DJ, Dear JW, Lewis PS, Platt V, Coyle J, Masson M, et al. Mechanistic biomarkers provide early and sensitive detection of acetaminophen-induced acute liver injury at first presentation to hospital. Hepatology. 2013;58(2):777-87. doi: 10.1002/hep.26294. [PubMed: 23390034]. [PubMed Central: PMC3842113].

25. Wu C, Zhang J, Cao X, Yang Q, Xia D. Effect of Mir-122 on human cholangiocarcinoma proliferation, invasion, and apoptosis through P53 expression. Med Sci Monit. 2016;22:2685-90. doi: 10.12659/MSM.896404. [PubMed: 27472451]. [PubMed Central: PMC4976756].

26. Wang $\mathrm{K}$, Zhang S, Marzolf B, Troisch P, Brightman A, Hu Z, et al. Circulating microRNAs, potential biomarkers for drug-induced liver injury. Proc Natl Acad Sci U S A. 2009;106(11):4402-7. doi: 10.1073/pnas.0813371106. [PubMed: 19246379]. [PubMed Central:
PMC2657429].

27. Salamin O, Jaggi L, Baume N, Robinson N, Saugy M, Leuenberger N. Circulating microRNA-122 as potential biomarker for detection of testosterone abuse. PLoS One. 2016;11(5). e0155248. doi: 10.1371/journal.pone.0155248. [PubMed: 27171140]. [PubMed Central: PMC4865044].

28. Sharapova T, Devanarayan V, LeRoy B, Liguori MJ, Blomme E, Buck W, et al. Evaluation of miR-122 as a serum biomarker for hepatotoxicity in investigative rat toxicology studies. Vet Pathol.2016;53(1):211-21. doi: 10.1177/0300985815591076. [PubMed: 26123229].

29. Chang J, Guo JT, Jiang D, Guo H, Taylor JM, Block TM. Liver-specific microRNA miR-122 enhances the replication of hepatitis $C$ virus in nonhepatic cells. J Virol. 2008;82(16):8215-23. doi: 10.1128/JVI.02575-07. [PubMed: 18550664]. [PubMed Central: PMC2519557].

30. Zhang X, Zhang Z, Dai F, Shi B, Chen L, Zhang X, et al. Comparison of circulating, hepatocyte specific messenger RNA and microRNA as biomarkers for chronic hepatitis B and C. PLoS One. 2014;9(3). e92112. doi: 10.1371/journal.pone.0092112. [PubMed: 24643113]. [PubMed Central: PMC3958472]. 